\title{
PERFORATED CONGENITAL ENTERIC DUPLICATION CYST MIMIC AS APPENDICULAR PATHOLOGY: A RARE CASE
}

\author{
Baskaran Dakshnamoorthy ${ }^{1}$ \\ 1 Professor and HOD, Department of Paediatric Surgery, KAPV Government Medical College and MGM Government Hospital, \\ Trichirappalli, Tamilnadu.
}

\section{ABSTRACT}

We report a case of perforated enteric duplication cyst, which was preoperatively diagnosed as appendicular mass. Duplication cysts are rare gastrointestinal congenital abnormalities and can occur anywhere within the gastrointestinal tract, may be located anywhere from the mouth to the anus. Signs and symptoms are dependent upon the location of the lesion. Perforated Enteric duplication mimic as appendicular pathology is a rare presentation in children.

\section{KEYWORDS}

Perforated Enteric Duplication; Congenital Enteric Duplication Cyst; Appendicular Pathology; Enteric Tubular Duplication.

HOW TO CITE THIS ARTICLE: Dakshnamoorthy B. Perforated congenital enteric duplication cyst mimic as appendicular pathology: a rare case. J. Evolution Med. Dent. Sci. 2016;5(57):3964-3965, DOI: 10.14260/jemds/2016/905

\section{INTRODUCTION}

Enteric duplication cysts are uncommon congenital malformation that may be found anywhere from mouth to anus. Duplications are typically located on the mesenteric area of the intestine. They are lined by alimentary tract mucosa. Usually, they present as an incidental finding in patient with other conditions. The pathogenesis is best explained by an abnormal adherence of the endodermal roof of the embryonic gut to the developing notochord. The distribution and variety of duplication is reflected by their diverse presentation which include obstruction, haemorrhage, infection, inflammation, perforation or intussusception. A small bowel duplication cyst is the most common type and the ileum is the most common location whereas rectal, duodenal, gastric and thoracoabdominal locations are extremely rare. They share a common muscular wall and blood supply with the native intestine and have variable communication with the enteric lumen. Gastric mucosa in a duplication lead to peptic ulceration, bleeding and perforation with peritonitis.

The diagnosis is often not established before surgery. The preferred treatment for a small cystic or tubular type involves segmental resection along with the adjacent intestine. Surgical complications are related to size, location; communication with the gastro, careful preoperative assessment and appropriate surgery are the essential steps to a successful outcome.

\section{CASE REPORT}

A 7-year-old male child was admitted in our hospital who had repeated episodes of right-sided abdominal pain with nausea and non-bilious vomiting. A movable mass was palpated in the right iliac fossa.

Clinically, the child was diagnosed and planned to manage for appendicular pathology. At laparotomy by Lanz incision, a six inches length, tubular, distally-communicating duplication

Financial or Other, Competing Interest: None.

Submission 08-06-2016, Peer Review 02-07-2016,

Acceptance 08-07-2016, Published 18-07-2016.

Corresponding Author:

Dr. Baskaran Dakshnamoorthy,

Professor and HOD,

Department of Paediatric Surgery,

KAPV Government Medical College,

and MGM Government Hospital,

Trichirappalli-620017, Tamilnadu.

E-mail: debas_2000@yahoo.com

DOI: $10.14260 /$ jemds $/ 2016 / 905$ of the ileum was found. It was located on the mesenteric border and shared a common wall with the normal ileum.[1] $1.5 \mathrm{~cm}$ diameter size of perforation was found in the antimesenteric border of the duplication with normal appendix (Fig. 1). Segmental resection and end-to-end ileo-ileal primary anastomosis with vicryl 3-0 was performed. Excised specimen sent for histopathological examination. On seventh post-operative day, the child was discharged without any complication.

\section{DIAGNOSIS}

Since most intra-abdominal duplications are located in the ileum, preoperative diagnosis is not always possible. All basic investigations were within normal limit. Ultrasound report was appendicular mass. Enteric duplication presenting as appendicular mass is rare. Erect chest with abdomen X-ray was normal. Based on the clinical findings and ultrasound report, a diagnosis of appendicular pathology was made and an exploratory laparotomy was planned. Usually, the duplication of enteric cyst presents with vague symptoms in children suggestive of other pathology, making diagnosis very difficult and should be a differential diagnosis in child presenting with right iliac fossa pain.

\section{DISCUSSION}

Often the cysts are lined by gastric mucosa and occasionally acid peptic digestion of the cyst wall may result in perforation and haemorrhage. Abdominal duplications may be cystic or tubular and often are amenable to complete operative excision. A palpable mass and symptoms of intestinal obstruction such as vomiting were associated with duplications derived from the mid- or hindgut. The most common symptoms were vomiting and abdominal pain. In our patient, a segmental resection of the perforated tubular duplicated bowel with primary anastomosis was performed. Complete excision of the duplication is the procedure of choice rather than marsupialisation and mucosal stripping.[2]

Adults may experience similar symptoms with acute presentations such as haemorrhage from ulceration or malignant transformation within the duplication. ${ }^{[3]}$ Unrecognized, asymptomatic cysts may be the site of adenocarcinoma during adult life. Complications such as haemorrhage and malignant degeneration are associated with duplication cysts.[4] 


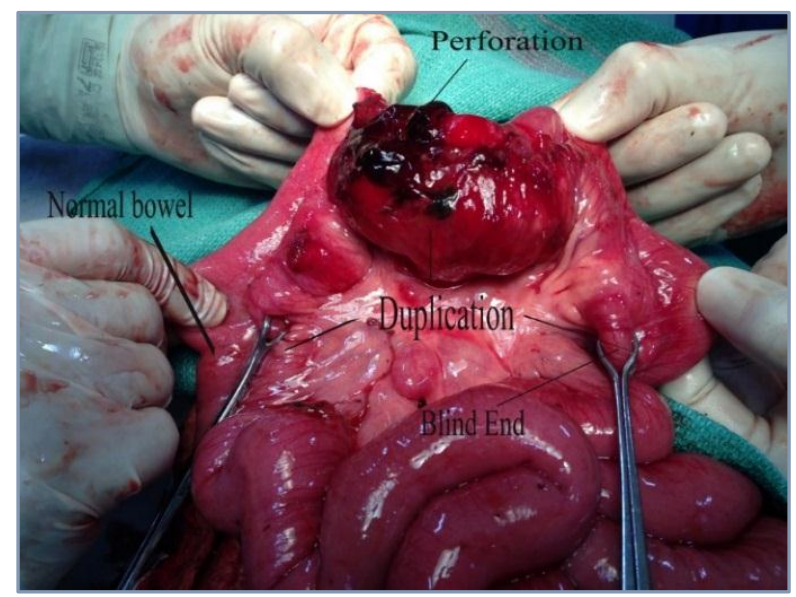

Fig. 1: Per-Operative Image

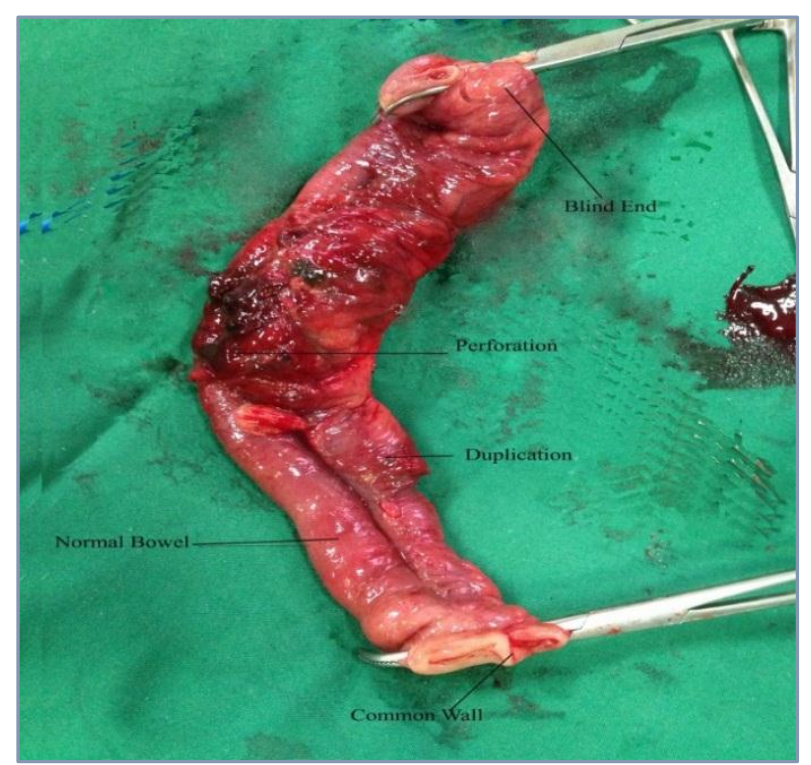

Fig. 2: Resected Perforated Duplication Enteric Cyst

\section{CONCLUSION}

Small bowel enteric duplication cyst is the most common type of enteric duplication cyst and the ileum is the most common site.[5] Enteric duplication cysts usually share a common wall with the normal intestine and have a common blood supply, so it is mandatory to remove the adjacent bowel segment along with duplication cyst (Fig. 2). Excision is recommended for symptomatic cases or when a complication arises. However, to date there is no consensus on the management of asymptomatic cases.[6] In our case, the child had a symptomatic (Perforation) duplication cyst and underwent surgical excision. There are only five cases reported in the literature up till the year 2000 including one adult case.[7]

\section{REFERENCES}

1. Srivastava P, Gangopadhyay AN, Kumar V, et al. Noncommunicating isolated enteric duplication cyst in childhood. Journal of Paediatric Surgery 2009;44(7):e910.

2. Ladd WE, Scott HW. Esophageal duplications or mediastinal cysts of enteric origin. Surgery 1944;16(2): 815.

3. Macpherson RI. Gastrointestinal tract duplications: clinical, pathologic, etiologic, and radiologic considerations. Radiographics 1993;13(5):1063-80.

4. Kim SK, Lim HK, Lee SJ, et al. Completely isolated enteric duplication cyst: case report. Abdominal Imaging 2003; 28(1):12-4.

5. Cheng G, Soboleski D, Daneman A, et al. Sonographic pitfalls in the diagnosis of enteric duplication cysts. American Journal of Roentgenology 2005;184(2): 521-5.

6. Lund DP. Alimentary tract duplications. In: Grosfeld JL, O'Neill JA, Fonkalsrud EW, et al. (eds) Pediatric Surgery. $6^{\text {th }}$ ed. Mosby, St Louis, Mo, USA 2006:1389-98.

7. Islah MAR, Hafizan T. Perforated ileal duplication cyst presenting with right iliac fossa pain mimicking perforated appendicitis. Med J Malaysia 2008;1:63-4. 